
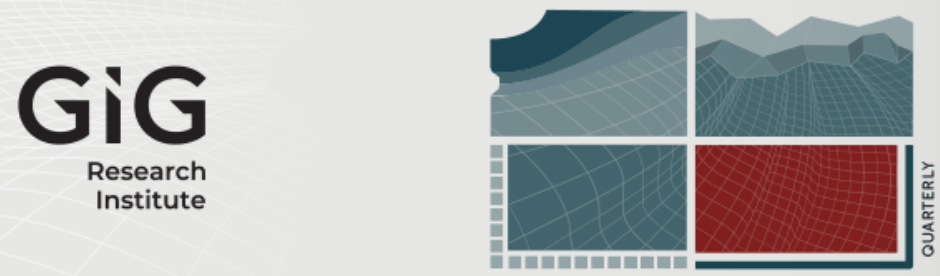

JOURNAL

OF

SUSTAINABLE

MINING

Volume 19 | Issue 4

Article 7

2020

\title{
The Acoustic Camera as a Tool to Identify Belt Conveyor Noises
}

Author(s) ORCID Identifier:

Piotr Bortnowski (iD) 0000-0002-6647-6234

Anna Nowak-Szpak (iD) 0000-0001-6102-5277

Maksymilian Ozdoba (iD) 0000-0002-3364-9442

Robert Król (iD 0000-0002-2529-1890

Follow this and additional works at: https://jsm.gig.eu/journal-of-sustainable-mining

Part of the Mechanical Engineering Commons, Mining Engineering Commons, and the Sustainability Commons

\section{Recommended Citation}

Bortnowski, Piotr; Nowak-Szpak, Anna; Ozdoba, Maksymilian; and Król, Robert (2020) "The Acoustic Camera as a Tool to Identify Belt Conveyor Noises," Journal of Sustainable Mining: Vol. 19 : Iss. 4 , Article 7.

Available at: https://doi.org/10.46873/2300-3960.1036

This Research Article is brought to you for free and open access by Journal of Sustainable Mining. It has been accepted for inclusion in Journal of Sustainable Mining by an authorized editor of Journal of Sustainable Mining. 


\title{
The Acoustic Camera as a Tool to Identify Belt Conveyor Noises
}

\begin{abstract}
This paper explores the possibilities of using an acoustic camera as a tool that allows the verification of the correct construction and operation of individual elements of a belt conveyor. Based on the simultaneously recorded components - a video camera and measuring microphones, the sound pressure level map of the belt conveyor was created. The tests were carried out in laboratory conditions and covered the location and identification of individual noise sources. The verification consists not only of searching for dominant sound sources, but above all, of searching for frequencies in the analysed spectrum that should not occur during their proper operation. The tests allow for the identification of frequencies and the determination of the sound pressure level for three noise sources: the electric motor noise, the idler roll bearing noise as well as the noise on the tail pulley caused by belt misalignment.
\end{abstract}

\section{Keywords}

belt conveyor, noise sources, noise location, acoustic camera

Creative Commons License

(c) (i)

This work is licensed under a Creative Commons Attribution 4.0 License. 


\title{
The acoustic camera as a tool to identify belt conveyor noises
}

\author{
Piotr Bortnowski, Anna Nowak-Szpak*, Maksymilian Ozdoba, Robert Król
}

Wrocław University of Science and Technology, Faculty of Geoengineering, Mining and Geology, Department of Mining and Geodesy, Na Grobli 15, 50-421, Wroclaw, Poland

\begin{abstract}
This paper explores the possibilities of using an acoustic camera as a tool that allows the verification of the correct construction and operation of individual elements of a belt conveyor. Based on the simultaneously recorded components - a video camera and measuring microphones, the sound pressure level map of the belt conveyor was created. The tests were carried out in laboratory conditions and covered the location and identification of individual noise sources. The verification consists not only of searching for dominant sound sources, but above all, of searching for frequencies in the analysed spectrum that should not occur during their proper operation. The tests allow for the identification of frequencies and the determination of the sound pressure level for three noise sources: the electric motor noise, the idler roll bearing noise as well as the noise on the tail pulley caused by belt misalignment.
\end{abstract}

Keywords: belt conveyor, noise sources, noise location, acoustic camera

\section{Introduction}

B elt conveyors are the most common means of transporting bulk materials in the mining industry. The effectiveness and reliability of its operation depends not only on the correctness of its design and construction, but above all, on maintaining this correctness throughout its working life. Therefore, it is necessary to monitor important parameters of its operation and diagnose the technical condition in order to detect early signs of deterioration. Thanks to this, we are able to prevent the technical threats or eliminate them early on. The complexity of the MRO (maintenance, repair and operation) process in conveyor transport has been the subject of many publications [1-3] and as an important topic in this industry, it requires efficient diagnostic tools.

Currently, special attention is being paid to the need for of minimizing the negative impact of noise emissions on the environment. It is essential for implementing technological processes and decision- making in the mining industry on new investments. Defined by applicable law [4-8] The 2030 National Environmental Policy (PEP2030) is a set of comprehensive actions (directions of interventions and strategic projects) aimed at creating conditions necessary for the implementation of environmental protection, in accordance with the principle of sustainable development. A number of challenges was identified [9] in the development of the country, which partly provide the grounds for taking intensified actions in particular areas. One of which is the increasingly significant adverse impact of the environment on human health, in which noise has been identified as a (relatively) new problem [9].

Excessive noise poses a severe threat to human health as well as affects animal welfare, and is therefore a particularly destructive phenomenon. The conveyor belt, as a group of modules connected in series, is a significant source of noise.

As systems operating most often in the all-day cycle and being a linear source of noise, they are very obtrusive factors for employees of industrial plants as well as residents of nearby areas [10]. Noise standards for the location of conveyors are

Received 15 November 2020; revised 17 December 2020; accepted 29 December 2020.

Available online 31 December 2020.

* Corresponding author.

E-mail address: anna.nowak-szpak@pwr.edu.pl (A. Nowak-Szpak). 
usually exceeded, especially operating at night. Thus, belt conveyors largely determine the generated noise of the entire technological line. For this reason, a noise reduction of these particular modules is especially required. The overall noise level for the entire transport system depends on the individual major noise sources, and the identification and location of these sources is an important step in the overall noise reduction process [11].

The issues related to the identification of noise emission from the conveyor belt can be found in many publications. The approach to measuring its emissions understandably depends, on the purpose of such tests. The most common group of publications is those constituting part of The Environmental Impact Reports and research on noise at workplaces. Such noise analyses are often supplemented with measurements of noise emissions at characteristic points of the route-as reference data for modelling acoustic impact. A characteristic feature of these publications is the treatment of the belt conveyor as a whole, without taking into account the features related to its structure (efficiency, speed, geometric parameters, etc.) and without considering the differences of these parameters on individual sections of the belt conveyor route. The proposed solutions to reduce excessive noise also concern the installation of barriers completely separating the emitter [10,12].

Publications describing the noise emitted by different elements comprising the conveyor belt are diverse, both because they relate to advertising materials of companies producing individual elements of the conveyor (idlers, pulleys, belts, bearings), as well as scientists who publish the results of their research. Conveyor noise generation mechanisms (Fig. 1) were summarized as follows:

- Idler Roll Bearing Noise,

- Idler Roll Shell Noise,

- Belt Idler Interaction,

- Air Pumping, Belt/Idler Roll,

- Structure-borne Noise - conveyor support structure [13].

The authors of various publications agree that the dynamic interaction at the interface between the belt and the rotating idler is the most dominant, but in the rest of their research they focus on measuring and modifying the idlers themselves [13-18]. In each of the above-mentioned publications, noise measurements were made with the use of a sound level meter or a set of several sound level meters. Some of the measurements were additionally supplemented with vibration registrations using piezometric accelerometers [18].

In recent years, a team of scientists from Košice has put forward a series of articles presenting the possibilities of using an acoustic camera for the identification and analysis of sound sources during belt conveyor testing. The authors verified a two way research approach, which they defined as the global approach (i.e. of the entire conveyor) and the discrete approach (i.e. of the critical places emitting noise) [19]. They presented measurement results on the identification and analysis of the dominant sound sources, such as electric motors $[19,20]$ as well as a hopper (through which material is supplied into the conveyor belt) and a crusher.

In this article, we would like to develop the possibilities of using an acoustic camera as a tool which

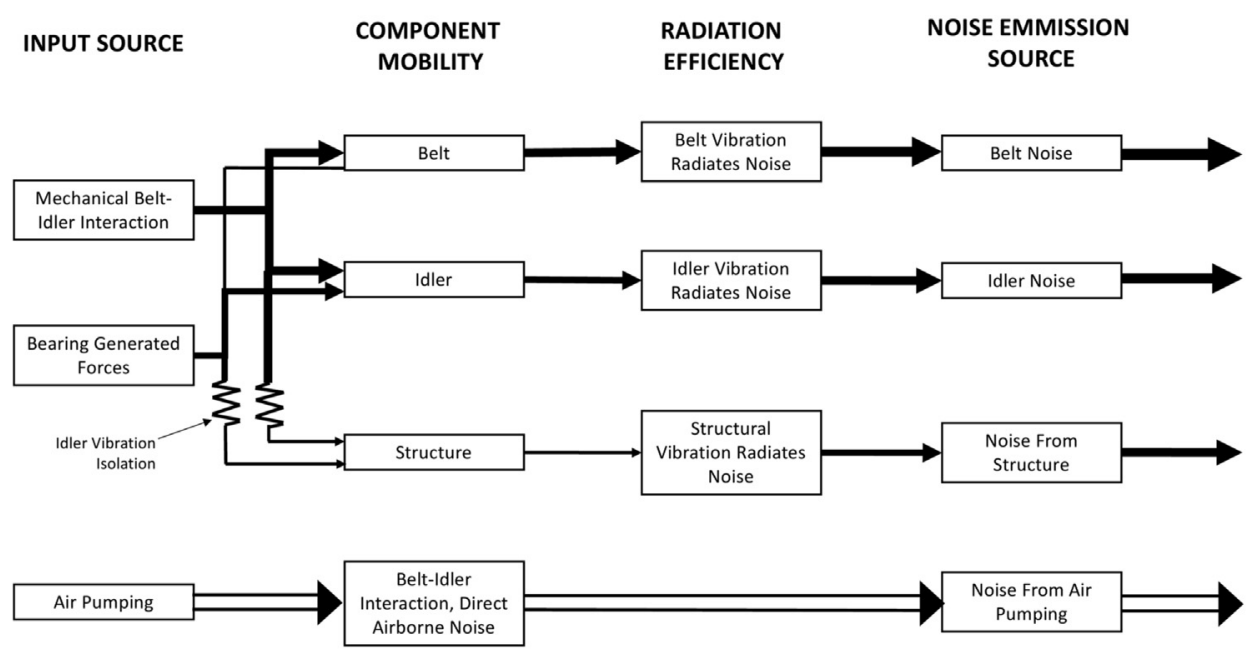

Fig. 1. Conveyor Noise Generation Mechanisms [13]. 
allows the verification of the correct construction and operation of individual elements of a belt conveyor. The verification consists not only of searching for dominant sound sources, but above all, of searching for frequencies in the analysed spectrum that should not occur during the proper operation of the conveyor and all its elements.

\section{Materials and methods}

The test was performed with an acoustic camera (Fig. 2). By combining two components - a video camera and measuring microphones, the device allows for the simultaneous location and identification of individual noise sources. The digital camera captures the image of the noise emitting device, and at the same time the microphone systems record the sound pressure (sound). This allows for the simultaneous measurement of sound pressure and sound source direction localization. The acoustic camera works based on beamforming principles-enabling accurate calculation of the specific runtime delays of acoustic sound emissions radiating from several sources to the individual microphones of an array [21]. It is possible due to the appropriate arrangement of the sensor array. The final step is to combine the optical and acoustic images into a single unit, in a form of is a color-coded map of the sound pressure level.

The measurements were carried out on a rig for testing the intermediate drive for a belt conveyor in the Machine Systems in Mining Laboratory, at the

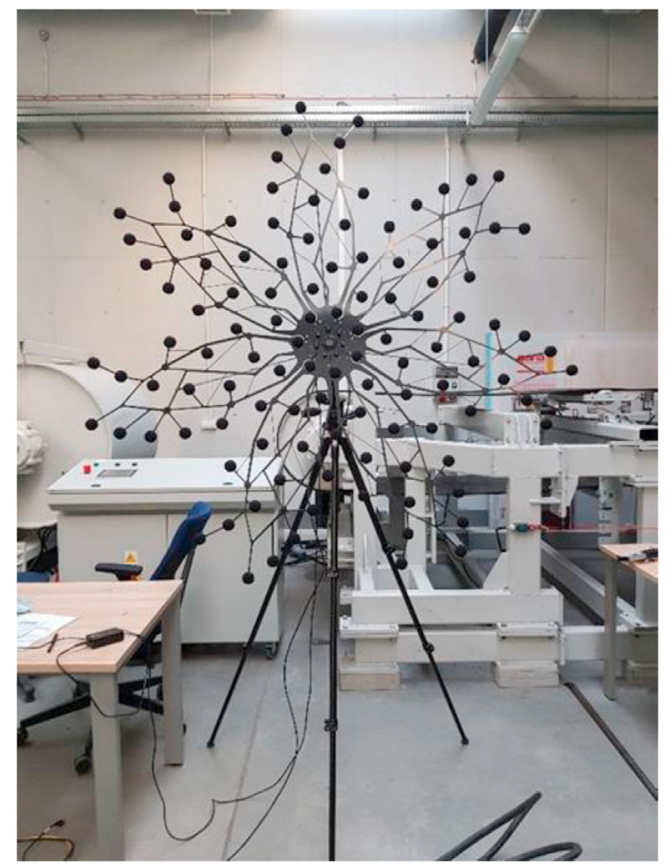

Fig. 2. The acoustic camera used in the measurements.
Wroclaw University of Science and Technology. Research in laboratory conditions allows for the elimination of acoustic phenomena that could occur in the actual operation of a mine. For the purpose of the test, the rig was adapted: the drives were disconnected, and only the intermediate drive was assumed as the test object. That minimized additional noise sources that could interfere with the noise identification of individual components.

The arrangement of individual objects in the laboratory was reorganized. No objects were located between the tested rig and the acoustic camera, which may have been a source of potential interference and reflections. Due to the location of the rig in short distance from one of the walls of the room, additional acoustic panels were used. The arrangement of individual objects is shown in the diagram below (Fig. 3).

The location of the camera in relation to the conveyor is limited by the maximum and minimum measuring range of the microphones used. In most cases, the minimum recommended distance from the test object is $4 \mathrm{~m}$. For these test condition an acoustic camera was placed at a fixed distance of $4.1 \mathrm{~m}$ from the conveyor structure. The $10 \mathrm{~s}$ time history of the acoustic signal was recorded (Fig. 4) with the sampling frequency of $800 \mathrm{~Hz}$. The conveyor noise measurements were made with the acoustic camera consisting of 112 MEMS-microphones, with a resolution of 24 bits and a maximum sampling frequency of $48 \mathrm{kHz}$. The frequency range of a microphone is from $10 \mathrm{~Hz}$ (in practice this value is closer to $20 \mathrm{~Hz}$ ) to $24 \mathrm{kHz}$. The operating range was defined as $<33 \mathrm{~dB}-120 \mathrm{~dB}$, with dynamics up to $40 \mathrm{~dB}$.

All tests were carried out for one configuration of the conveyor operation: constant linear belt speed of $2.76 \mathrm{~m} / \mathrm{s}$ and constant belt tensioning force of $25 \mathrm{kN}$. Measurements were made for the EP1250/5 textile belt with a width of $0.4 \mathrm{~m}$. The drive motor nominal

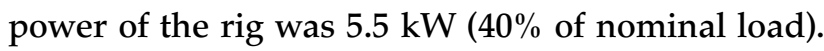
The distance between the axis of the tail and the drive pulley was $5 \mathrm{~m}$. There was one upper idler installed hallway through the length of the rig (Fig. 3).

Acquisition and initial data processing was carried out using the dedicated Noise Inspector software. The recorded time signals were then processed in the MATLAB environment. The dominant and characteristic frequencies in the noise time history were found using the discrete Fourier transform. The result of using FFT is the ability to describe the signal amplitude as a function of frequency. The Noise Inspector software additionally enables the spectra to be generated and where the amplitude is 


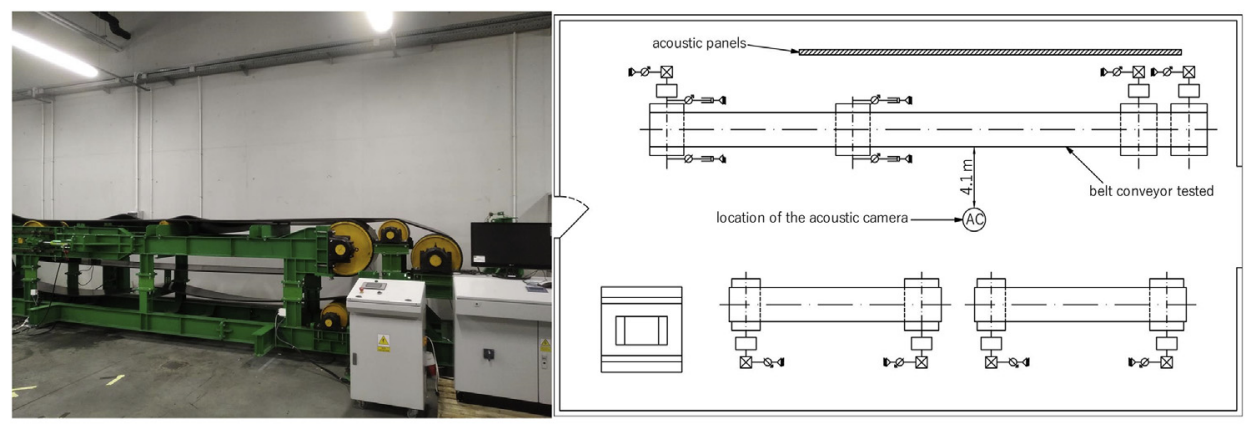

Fig. 3. Schematic top-view of the laboratory arrangement.

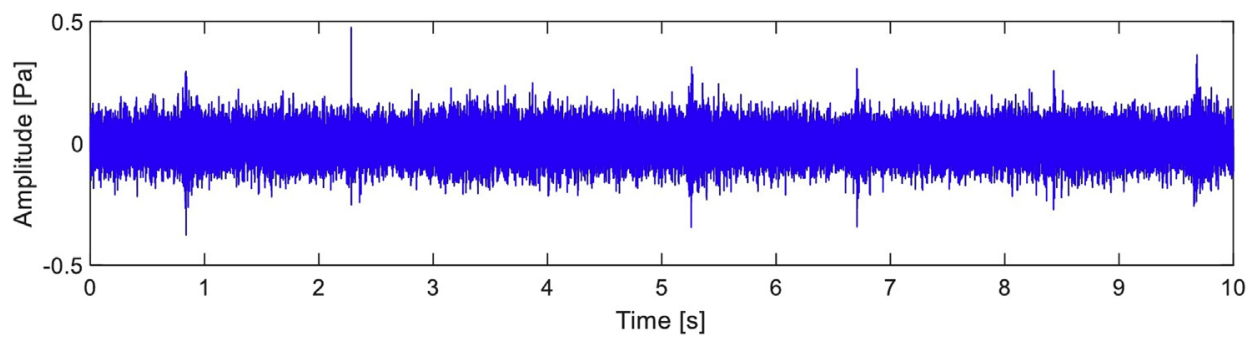

Fig. 4. Conveyor noise time history - the acoustic signal (variant of the conveyor operation with one idler, at the linear belt speed of $2.76 \mathrm{~m} / \mathrm{s}$ ).

described by the time and frequency function. The knowledge of these frequencies allows for an effective search for noise sources with the use of an acoustic camera. Result arrays were generated for the found characteristic frequencies.

\section{Results and discussion}

\subsection{Preliminary testing}

The first stage of the study was the analysis of noise sources and acoustic backgrounds in the laboratory. External noise sources make the measurements with an acoustic camera more difficult and distort the results and affect the recorded sound pressure level values. In stationary conditions the background signal has the characteristics of an ergodic process therefore the elimination of the background noise might be done by filtering it. For real-life conditions where the background noise is not constant, the identification of external noise sources should be based on signal spectrum analysis and the identified interference frequencies. The signal spectrum is achieved by using the Discrete Fourier Transform algorithms. The background sound pressure level for the test room was about $57.42 \mathrm{~dB}$, with dominant low and medium frequencies up to $2 \mathrm{kHz}$. The acoustic background spectrum is shown in Fig. 5.

Preliminary analysis of noise sources allows for efficient use of the acoustic camera and a significant reduction of time in which the results are obtained. The identification of noise sources requires the definition of a frequency range. The resulting sound distribution maps depend primarily on the accuracy of the specified frequency ranges. Manually analysing the spectrum for characteristic frequencies is extremely impractical. It was initially assumed that the main sources of noise in test conditions would be the conveyor drive and the upper idler. On this basis, the initial frequency range for further research was determined. The omission of this step, as well as the lack of narrowing the frequency range, renders the acoustic camera useless. The resulting acoustic colour scale map is so blurred (Fig. 6) that locating the noise sources is not possible.

\subsection{Selected noise sources research}

The mere use of an acoustic camera and dedicated Noise Inspector software does not guarantee the success of the analysis. Recordings obtained this way require an analysis of the signal frequency distribution (Fig. 7). This type of distribution analysis allows for the determination of the dynamics of individual acoustic phenomena and for the determination of dominant frequencies. This is a necessary step in locating potential noise sources. Lack of this knowledge caused the obtained acoustic colour scale maps to be very blurred.

The analysis of the obtained signal spectra (Fig. 7) showed that the dominant frequency in the signal is 


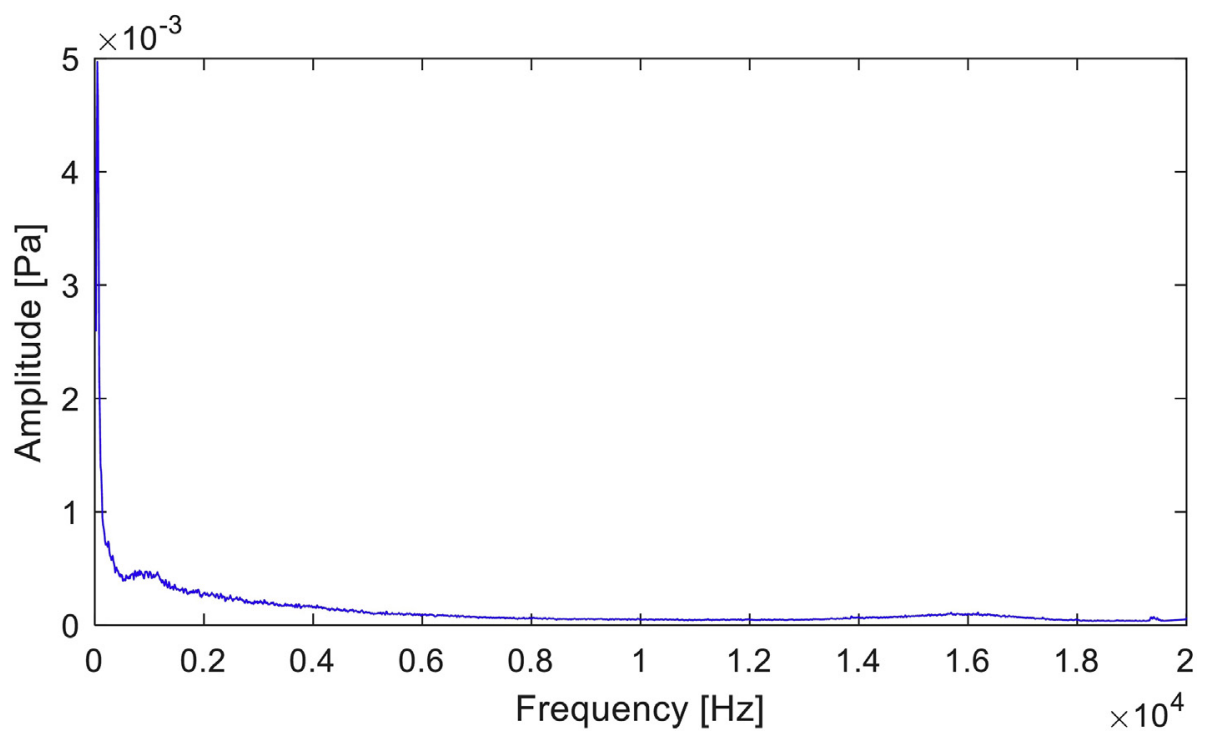

Fig. 5. Spectrum of acoustic background.

$8 \mathrm{kHz}$ and its harmonics (i.e., multiples) are $12 \mathrm{kHz}$ and $16 \mathrm{kHz}$. Measurements made with an acoustic camera, more precisely a spectrogram, representing the extension of the signal spectrum over time (Fig. 8) - made it possible to definitively associate this frequency with the noise generated by the drive of the laboratory conveyor motor (Fig. 9). The generated maximum sound pressure level is $65.4 \mathrm{~dB}$ for a frequency of $8004 \mathrm{~Hz}$ (Table 1) (see Fig. 10).

The noise generated by an electric motor is the result of electromagnetic processes taking place inside it. This frequency is equal to twice the frequency of the power source, but it also depends on the motor design parameters, such as the number of pole pairs. Research in this area has shown that these are usually higher harmonics of the fundamental frequency [22-24].

Apart from the frequencies related to the noise generated by the drive motor, low frequencies, up to $700 \mathrm{~Hz}$, are dominant. This is where the conveyor

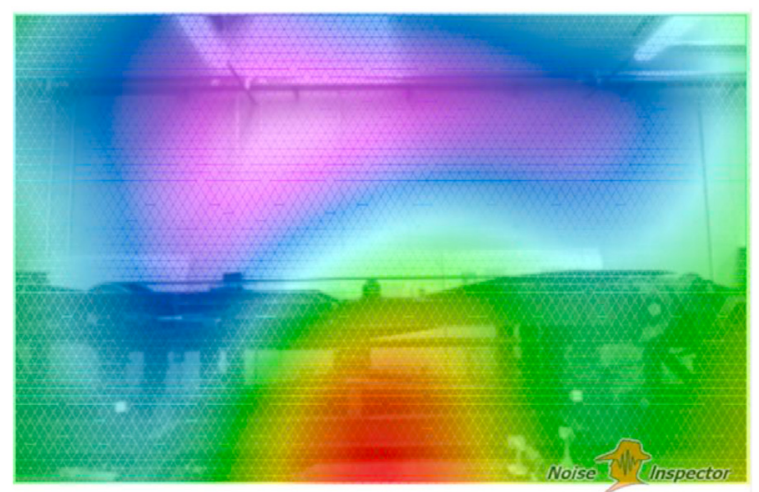

Fig. 6. Acoustic colour scale map with no specific frequency range. makes the most noise. According to literature [25], the machines used in most industrial plants generate noise with a dominant octave band centre frequency $(\mathrm{OBF})$ in the low and mid-range (from $22 \mathrm{~Hz}$ to $2 \mathrm{kHz}$ ). It is believed that for frequencies up to $600 \mathrm{~Hz}$ the reduction and suppression of noise is most effective [26-28].

The second localized noise source of the conveyor belt is related to the interaction of the idler and the conveyor belt (Fig. 11). The rotating idler generates noise as it rolls over the belt. The noise produced may be the result of the frictional cooperation of the conveyor belt with the idler shell, the vibrations of the idler shell or the wear-out of the roller bearing [17]. In case of the belt-roller interaction, the main source of noise is usually the roller shell [16]. Each of these noise factors occur at different frequencies. The noise of the roller bearings is usually located in the range from 1000 to $3000 \mathrm{~Hz}$, while we are able observe vibration of the bearings up to $1000 \mathrm{~Hz}$. The noise resulting from the belt-idler interaction (the result of idler rotation) in form of belt vibrations or idler support vibrations, is included in the low frequency range up to $100 \mathrm{~Hz}$ [17], The acoustic camera does not allow for measurements in the lowest frequency ranges $(<20 \mathrm{~Hz})$. The identified idler generates the maximum sound pressure level of $39.9 \mathrm{~dB}$ for the frequency of $1570 \mathrm{~Hz}$ hence. It can be clearly indicated that it is caused by the bearing. Roller bearing noise may be caused by damages in raceways and/or rolling elements resulting from wearout or use negligence [29].

The third and last localized source of noise is caused by the slippage between the belts and the 


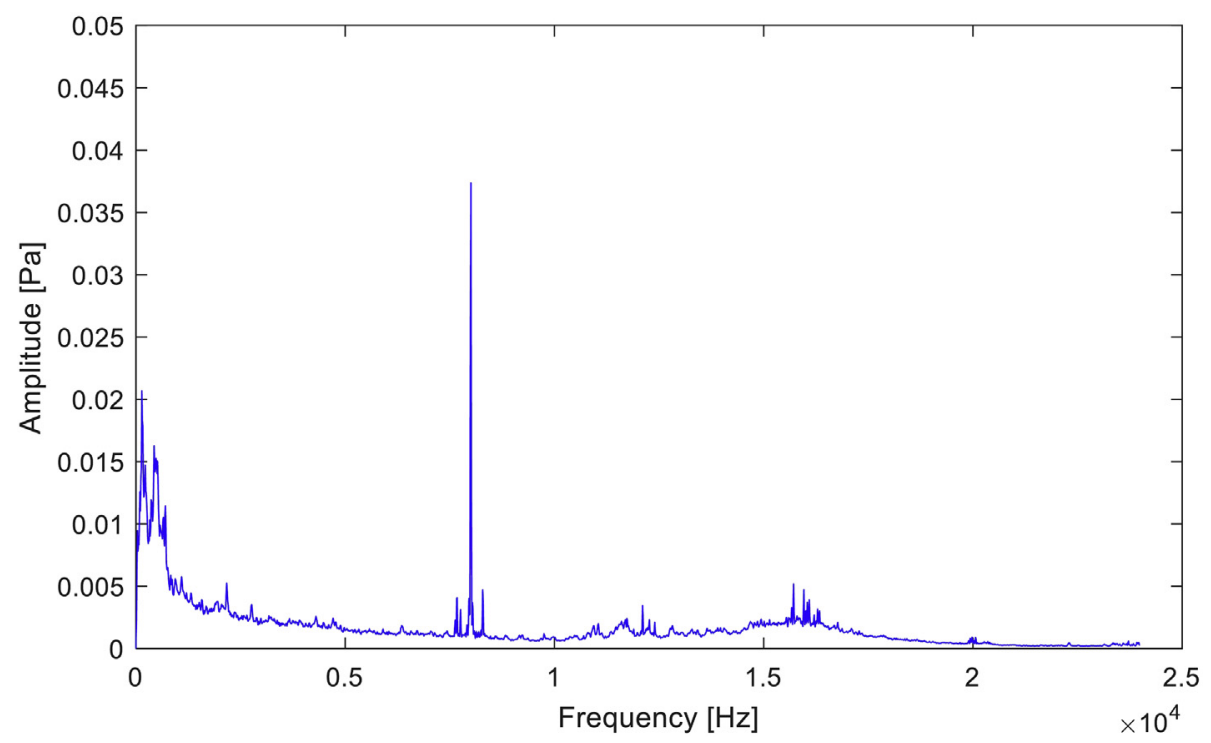

Fig. 7. Signal spectrum over the entire frequency range.

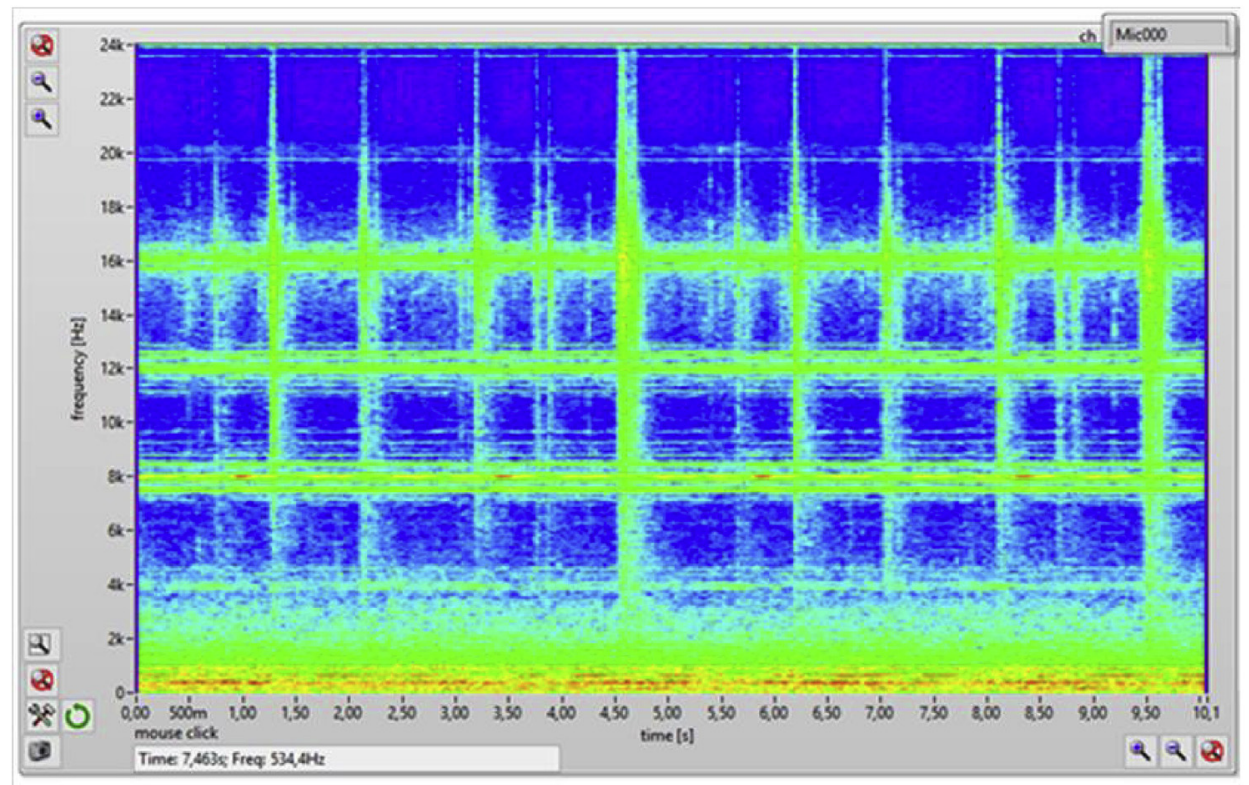

Fig. 8. The spectrum of frequencies of a signal in time. Visible harmonic vibrations occurring at multiples of the fundamental frequency.
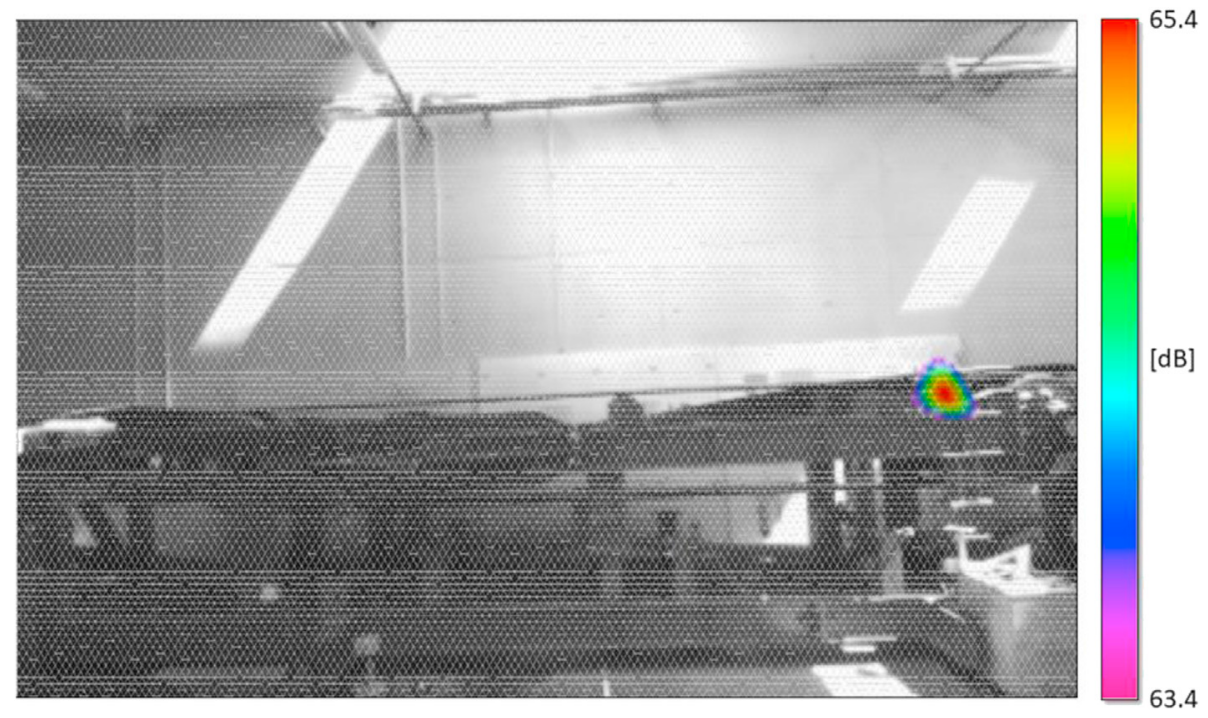

Fig. 9. Noise generated by the engine-belt conveyor drive. 
Table 1. Sound pressure level measurement results for localized noise sources.

\begin{tabular}{lll}
\hline Localized noise sources & $\mathrm{L}_{\mathrm{p}}[\mathrm{dB}]$ & $\mathrm{L}_{\mathrm{pA}}[\mathrm{dB}]$ \\
\hline Conveyor belt (in total) & 79.46 & 73.66 \\
Drive/electric motor & 65.40 & 65.40 \\
Idler & 39.90 & 39.90 \\
Belt misalignment on the tail pulley & 35.20 & 35.20 \\
\hline
\end{tabular}

pulleys (Fig. 12). There are many reasons that affect the belt's ability to track properly [30]. The most common are: little accuracy in the alignment between pairs of components, such as drive and tail pulley, or improper belt installation. A characteristic feature of this occurrence is the cyclical wandering of the belt along the pulley in the directions of its axis. The reason for this is the system's efforts to equalize the forces. It is influenced by, among other things, the tensioning force pressing the belt to the pulley, the coefficient of friction, and the alignment of conveyor elements. Misalignment is a real threat as it affects the stability of the operation, wear-out and failure of the belt, damage or breakage to the motors, motion failure, all of which may cause a risk of injury for people.

In order to prevent the wandering conveyor belts the guide idlers are used. They constitute a barrier limiting the space for the belt. Another way to reduce or even eliminate it is proper positioning of a pulley on a shaft.

A characteristic high-frequency noise is emitted during the belt wandering. The noise emission depends on the type of surfaces of the contacting

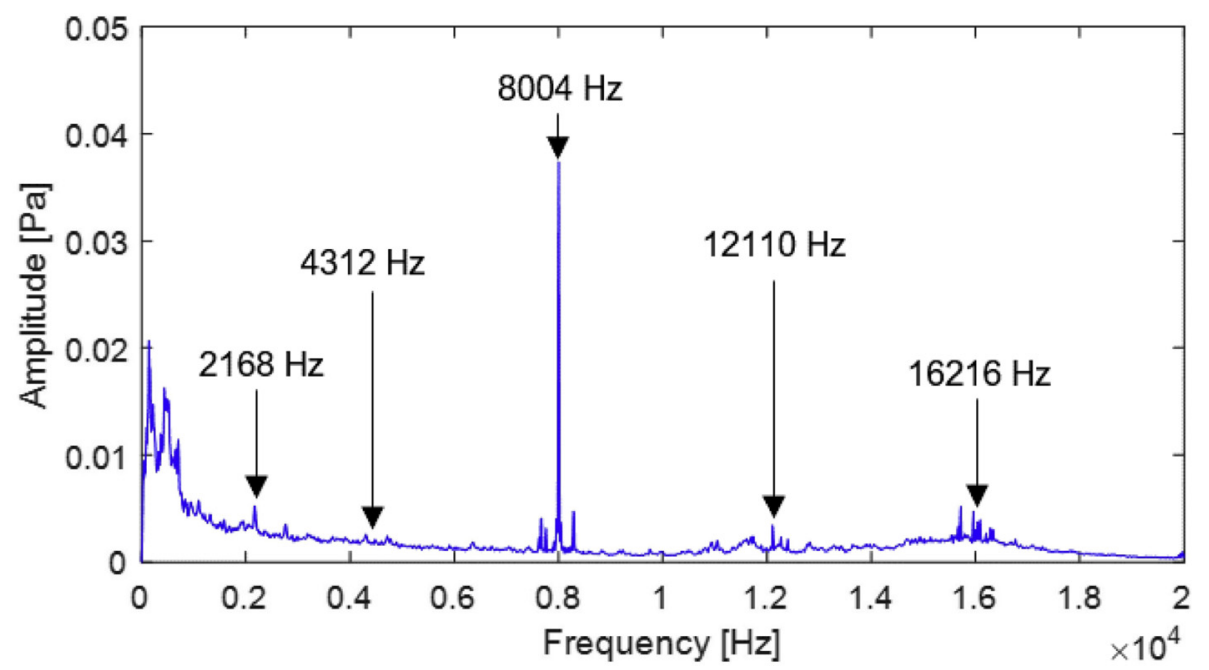

Fig. 10. Identified frequencies related to electric motor noise (high frequencies).

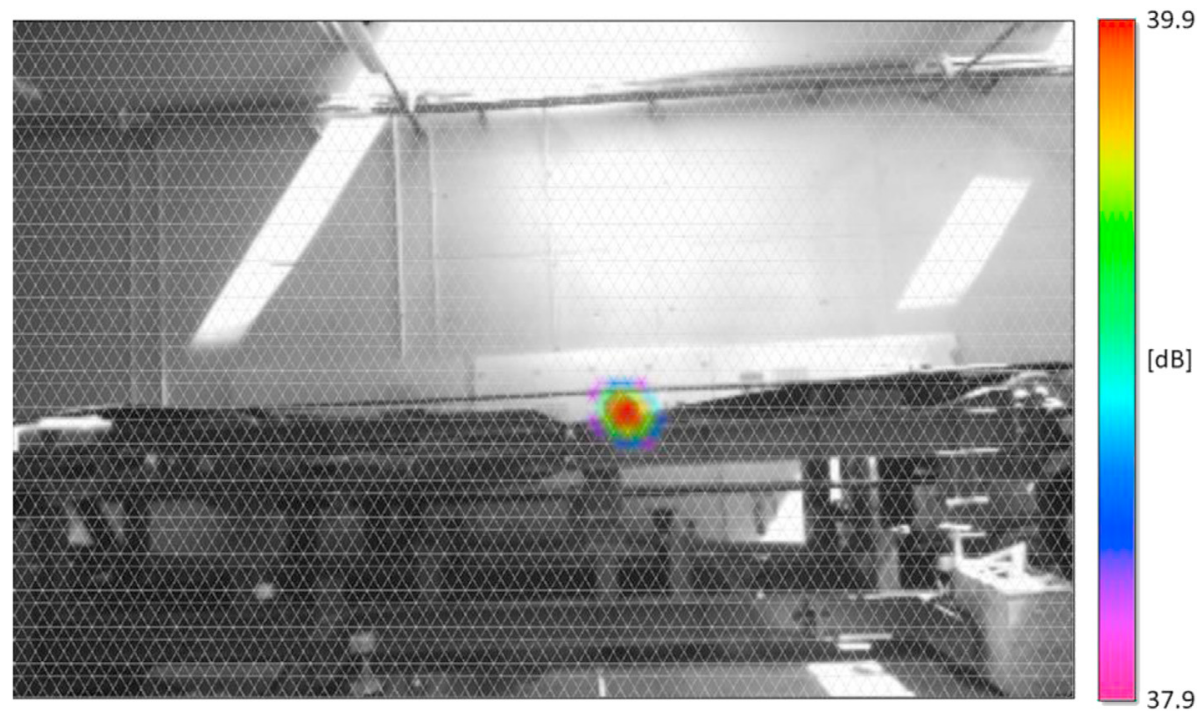

Fig. 11. Noise generated by the idler (roller bearing). 


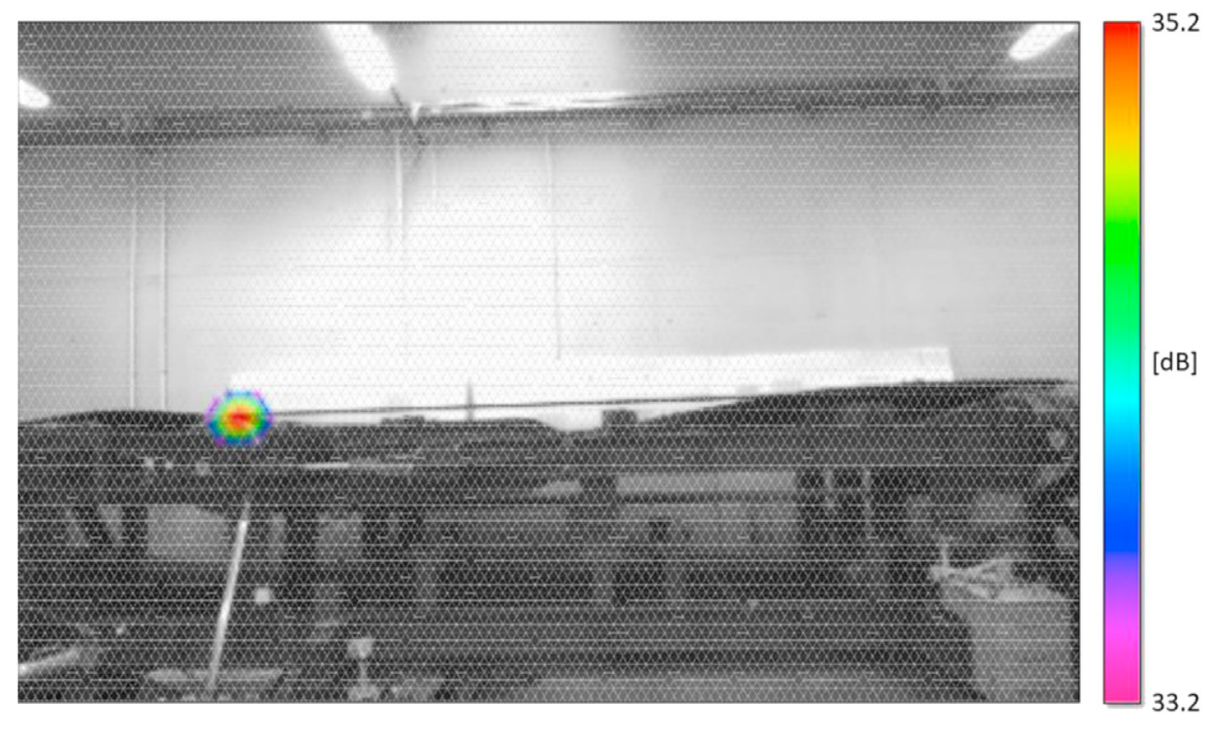

Fig. 12. Noise on the tail pulley caused by belt misalignment.

elements and the scale of the phenomenon (the radial sliding length). For the conducted research, it was measured that this phenomenon generates a maximum level of sound pressure of $35.2 \mathrm{~dB}$ at $2544 \mathrm{~Hz}$. However, many more high-frequency harmonics can be distinguished within the signal spectrum.

\section{Conclusions}

Testing with an acoustic camera allows for spatial location of the noise source. The recorded material, properly processed in the Noise Inspector program, allows for the investigation of noise sources with a specific frequency in the area of interest.

During the analysis of noise sources, attention was paid to high frequency components. In the signal spectrum, harmonics of the fundamental frequency of the engine noise were found, with the highest amplitude for the harmonics of $8 \mathrm{kHz}$. According to the theory, an electric motor generates high-frequency noise that comes from the frequency of the motor's supply voltage. The entire conveyor was located within the detection range of the measuring equipment, therefore the high-frequency components were clearly visible, located in the vicinity of the conveyor drive.

The highest concentration of noise sources is located in the low frequency range from 20 to $700 \mathrm{~Hz}$. This noise is the result of the movement of mechanical parts. One of the main sources of noise for belt conveyors, especially along the transport route, is the noise caused by the belt-idler interaction. The noise level generated by individual rotating elements cooperating with the belt can be directly related to their technical condition. Due to the low angular velocities (excluding the motor and drive gear), any frequencies of significant amplitude that may indicate a bad technical condition of a given element should be identified in the range of low and medium frequencies. These will be regular repetitive signals related to the operation of the bearings, friction of the worn components of gear cooperation. A typical noise related to the operation of the belt and idler is the noise of the idler bearing worn out due to operation. An acoustic camera allows for the location of noise at frequencies that characterize these elements. The conducted tests confirm that the spectrum analysis in search of bearing noise should be performed for the frequency range of $1000-3000 \mathrm{~Hz}$. This applies to the base frequency as well as subsequent harmonics. While analysing the recorded signal, distinctive high amplitude frequency components were observed. Found frequencies located in space which was the point of contact between the pulley and the belt. The source of this noise component is the lateral wandering of the belt, which causes a high frequency squeak from the rubber belt is slipping on the steel pulley.

The sound pressure level of the whole conveyor belt was $79.46 \mathrm{~dB}$. The acoustic camera allowed the location on three sources of noise within the laboratory conveyor:

- Electric motor - the drive of the belt conveyor, the sound pressure level is $65.4 \mathrm{~dB}$ for a frequency of $8004 \mathrm{~Hz}$, 
- Idler - the roller bearing noise with maximum sound pressure level of $39.9 \mathrm{~dB}$ for the frequency of $1570 \mathrm{~Hz}$,

- Belt misalignment on the tail pulley - the maximum sound pressure level of 35.20 for the frequency of $2544 \mathrm{~Hz}$.

The tests carried out in laboratory conditions show the potential of the acoustic camera. This tool allows for a quick analysis of noise sources. The field of application can be the broadly understood field of diagnostics of both moving mechanical parts and drive components. The spatial location allows the identification of phenomena that are difficult to describe theoretically due to the limited possibility of estimating the scale and the lack of theoretical models. This is perfectly demonstrated by an example of locating the noise caused by belt misalignment that should not occur during the proper operation of the conveyor.

The disadvantage of the method is the lack of the process' automation. A possible system of continuous monitoring of the conveyor condition based on an acoustic camera could help to prevent hazardous occurrences such as destabilization of the operation, wear-out and failure of the belt, damage or breakage to the motors, motion failure, all of which may cause a risk of injury for people. Another significant disadvantage of this method is the inability to analyse noise at very low frequencies.

\section{Ethical statement}

The authors state that the research was conducted according to ethical standards.

\section{Funding body}

This research received no external funding.

\section{Conflicts of interest}

None declared.

\section{References}

[1] Liptai P, Lumnitzer E, Moravec M, Piňosová M. Analysis and classification of noise sources of conveyor systems by sound visualizing on the postal package sorting line. Adv Sci Tech Res J 2018;12(4):172-6. https://doi.org/10.12913/22998624/100348.

[2] Molnár V, Fedorko G, Andrejiová $M$, Grinčová $A$, Michalik P. Online monitoring of a pipe conveyor. Part I: measurement and analysis of selected operational parameters. Measurement 2016;94:364-71.

[3] Lu Q, Wang X, Zhuang L. Research and design of monitoring system for belt conveyor. In: 2012 international conference on computer science \& service system. CSSS; 2012. https:// doi.org/10.1109/CSSS.2012.485.
[4] The Environmental Protection Act of 27 April 2001 (Consolidated text: Polish Journal of Laws of 2019, item 1396, as amended).

[5] Resolution No. 8 of the council of ministers of 14 February 2017 on the adoption of the strategy for responsible development until 2020 (with the perspective until 2030) official journal of the republic of Poland monitor Polski of 2017. 2017. item 260.

[6] Resolution No. 67 of the council of ministers of 16 July 2019 on the adoption of the "National environmental policy 2030 development strategy for the environment and water management". Polish Monitor; 2019. item 794.

[7] Single European act. Feb. 17, 1986. 0.J. L169/1 (1987).

[8] European Union. Consolidated version of the treaty on the functioning of the European union. 26 October 2012. OJ L. 326/47-326/390; 26.10.2012.

[9] National Environmental Policy 2030 - the development strategy for environment and water management area. Warsaw: Ministry of Climate; 2019.

[10] Sadowski J, Fąs T. Minimalizacja hałasu taśmociągu transportującego węgiel brunatny [Noise minimization of belt conveyor used for lignite coal transportation]. Inżynieria i Chemiczna 2014;53(2):113-5.

[11] Lutyński A. Identyfikacja poziomu hałasu na stanowiskach technologicznych $\mathrm{w}$ zakładach przeróbki kopalń węgla kamiennego. Górnictwo i Geoinżynieria 2006;30(3/4):173-80.

[12] Sadowski J. Wielowarstwowy ustrój dźwiękochlonno-izolacyjny zwłaszcza na ciągach przenośników taśmowych. 2006. Poland Patent 59682-2006.

[13] Brown S. Conveyor noise specification and control. In: Conference paper 2004 Annual Conference of the Australian Acoustical Society 3-5 November 2004. Proceedings of ACQUSTICS; 2004. p. 269-76.

[14] Ladányi G. Study on the noise emission of belt conveyor idler Rolls. Annals of the University of Petroşani. Mech Eng 2016;18:83-92.

[15] Gładysiewicz A. Metody redukcji hałasu przenośników taśmowych. Trans Przemyslowy i Maszyny Robocze 2010;3: 6-63.

[16] Sawicki W, Król R. Estimation of vibro-acoustic properties of idlers based on modal analysis. Min Sci 2006;VIII(1):179-85.

[17] Bartelmus W, Sawicki W. Noise of belt conveyors. Chapter 165. In: Mine planning and equipment selection 2000, 1st edition; 2000.

[18] Klimenda F, Kampo J, Hejma P. Vibration measurement of conveyor rollers. Proc Eng 2016;136:198-203. https://doi.org/ 10.1016/j.proeng.2016.01.197.

[19] Fedorko G, Liptai P, Molnar V. Proposal of the methodology for noise sources identification and analysis of continuous transport systems using an acoustic camera. Eng Fail Anal 2018;83: 30-46. https://doi.org/10.1016/j.engfailanal.2017.09.011.

[20] Liu X, Pei D, Lodewijks G, Zhao Z, Mei J. Acoustic signal based fault detection on belt conveyor idlers using machine learning. Adv Powder Technol 2020;31(7):2689-98. https:// doi.org/10.1016/j.apt.2020.04.034.

[21] Heinz GK. Modelling inherent communication principles of biological pulse networks. Syst Anal Model Simulat 1994; 15(2):51-158. https://doi.org/10.1007/s11831-016-9182-3.

[22] Nau SL, Gomez Mello HG. Acoustic noise in induction motors: causes and solutions. In: Industry applications society Forty-seventh annual conference; 2000.

[23] Janda $M$, Ondřej $V$, Vladimir $H$. Noise of induction machines. 2012.

[24] Sathyan S, Aydin U, Belahcen A. Acoustic noise computation of electrical motors using the boundary element method. Energies 0301 2020;13(1). https://doi.org/10.3390/en13010245. 1996-1073.

[25] Mahendra Prashanth K, Venugopalachar S. The possible influence of noise frequency components on the health of exposed industrial workers - a review. Noise Health 2011; 13(50):16-25. https://doi.org/10.4103/1463-1741.73996.

[26] Wang C, Gao H, Yu L, Yu T, Yan W, Xue Q. Portable lowfrequency noise reduction device for both small open and 
closed spaces. Shock Vib 2016. https://doi.org/10.1155/2016/ 6241935.

[27] Kuo SM, Morgan DR. Active noise control: a tutorial review. IEEE 1999;87(6):943-73. https://doi.org/10.1109/5.763310.

[28] Monaragala R. Knitted structures for sound absorption. Adv Knit Tech 2011:262-86.
[29] Dyer D, Stewart RM. Detection of rolling element bearing damage by statistical vibration analysis. J Mech Des 1978: 229-35.

[30] [Online]. Available: http://www.sparksbelting.com/blog/ conveyor-belt-tracking-common-causes-of-misalignmentchecklist. [Accessed 28 September 2020]. 